\title{
Core Elements of Outpatient Antibiotic Stewardship
}

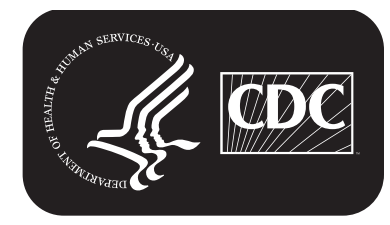




\section{CONTENTS}

Introduction 1

Background 1

Methods .. .4

Core Elements of Outpatient Antibiotic Stewardship .4

Future Directions 10

Conclusion 10

References 10

The MMWR series of publications is published by the Center for Surveillance, Epidemiology, and Laboratory Services, Centers for Disease Control and Prevention (CDC), U.S. Department of Health and Human Services, Atlanta, GA 30329-4027.

Suggested citation: [Author names; first three, then et al., if more than six.] [Title]. MMWR Recomm Rep 2016;65(No. RR-\#):[inclusive page numbers].

\section{Centers for Disease Control and Prevention}

Thomas R. Frieden, MD, MPH, Director

Harold W. Jaffe, MD, MA, Associate Director for Science

Joanne Cono, MD, ScM, Director, Office of Science Quality

Chesley L. Richards, MD, MPH, Deputy Director for Public Health Scientific Services

Michael F. Iademarco, MD, MPH, Director, Center for Surveillance, Epidemiology, and Laboratory Services

\section{MMWR Editorial and Production Staff (Serials)}

Sonja A. Rasmussen, MD, MS, Editor-in-Chief

Charlotte K. Kent, $\mathrm{PhD}$, MPH, Executive Editor Christine G. Casey, MD, Editor

Teresa F. Rutledge, Managing Editor

David C. Johnson, Lead Technical Writer-Editor

Catherine B. Lansdowne, MS, Project Editor

\section{Disclosure of Relationship}

CDC, our planners, presenters (or content experts), and their spouses/partners wish to disclose they have no financial interests or other relationships with the manufacturers of commercial commercial services, or commercial is no bias. Content will not include any discussion of the use, with the exception that some of the recommendations in might be inconsistent with package labeling. CDC did not accept commercial support for this continuing education activity. 


\title{
Core Elements of Outpatient Antibiotic Stewardship
}

\author{
Guillermo V. Sanchez, MPH, MSHS ${ }^{1}$ \\ Katherine E. Fleming-Dutra, $\mathrm{MD}^{1}$ \\ Rebecca M. Roberts, MS ${ }^{1}$ \\ Lauri A. Hicks, DO ${ }^{1}$ \\ ${ }^{1}$ Division of Healthcare Quality Promotion, CDC
}

\section{Summary}

The Core Elements of Outpatient Antibiotic Stewardship provides a framework for antibiotic stewardship for outpatient clinicians and facilities that routinely provide antibiotic treatment. This report augments existing guidance for other clinical settings. In 2014 and 2015, respectively, CDC released the Core Elements of Hospital Antibiotic Stewardship Programs and the Core Elements of Antibiotic Stewardship for Nursing Homes. Antibiotic stewardship is the effort to measure and improve how antibiotics are prescribed by clinicians and used by patients. Improving antibiotic prescribing involves implementing effective strategies to modify prescribing practices to align them with evidence-based recommendations for diagnosis and management. The four core elements of outpatient antibiotic stewardship are commitment, action for policy and practice, tracking and reporting, and education and expertise. Outpatient clinicians and facility leaders can commit to improving antibiotic prescribing and take action by implementing at least one policy or practice aimed at improving antibiotic prescribing practices. Clinicians and leaders of outpatient clinics and health care systems can track antibiotic prescribing practices and regularly report these data back to clinicians. Clinicians can provide educational resources to patients and families on appropriate antibiotic use. Finally, leaders of outpatient clinics and health systems can provide clinicians with education aimed at improving antibiotic prescribing and with access to persons with expertise in antibiotic stewardship. Establishing effective antibiotic stewardship interventions can protect patients and improve clinical outcomes in outpatient health care settings.

\section{Introduction}

Antibiotic resistance is among the greatest public health threats today, leading to an estimated 2 million infections and 23,000 deaths per year in the United States (1). Although antibiotics are life-saving drugs that are critical to modern medicine, infections with pathogens resistant to first-line antibiotics can require treatment with alternative antibiotics that can be expensive and toxic. Antibiotic-resistant infections can lead to increased health care costs and, most importantly, to increased morbidity and mortality (1). The most important modifiable risk factor for antibiotic resistance is inappropriate prescribing of antibiotics. Approximately half of outpatient antibiotic prescribing in humans might be inappropriate, including antibiotic selection, dosing, or duration, in addition to unnecessary antibiotic prescribing (2-4). At least 30\% of outpatient antibiotic prescriptions in the United States are unnecessary (5).

Antibiotic stewardship is the effort to measure antibiotic prescribing; to improve antibiotic prescribing by clinicians and use by patients so that antibiotics are only prescribed and used when needed; to minimize misdiagnoses or delayed diagnoses

Corresponding author: Katherine E. Fleming-Dutra, Division of Healthcare Quality Promotion, National Center for Emerging and Zoonotic Infectious Diseases, CDC. Telephone: 404-639-4243. E-mail: getsmart@cdc.gov. leading to underuse of antibiotics; and to ensure that the right drug, dose, and duration are selected when an antibiotic is needed $(1,0)$. Antibiotic stewardship can be used in all health care settings in which antibiotics are prescribed and remains a cornerstone of efforts aimed at improving antibiotic-related patient safety and slowing the spread of antibiotic resistance. The goal of antibiotic stewardship is to maximize the benefit of antibiotic treatment while minimizing harm both to individual persons and to communities.

\section{Background}

Improving antibiotic prescribing in all health care settings is critical to combating antibiotic-resistant bacteria (7). Approximately $60 \%$ of U.S. antibiotic expenditures for humans are related to care received in outpatient settings (8). In other developed countries, approximately $80 \%-90 \%$ of antibiotic use occurs among outpatients (9,10). During 2013 in the United States, approximately 269 million antibiotic prescriptions were dispensed from outpatient pharmacies (11). Approximately $20 \%$ of pediatric visits (12) and $10 \%$ of adult visits (3) in outpatient settings result in an antibiotic prescription. Complications from antibiotics range from common side effects such as rashes and diarrhea to less common adverse events such as severe allergic reactions (13). These adverse drug events lead to an estimated 143,000 emergency 
department visits annually and contribute to excess use of health care resources (13). Antibiotic treatment is the most important risk factor for Clostridium difficile infection (14). In 2011, an estimated 453,000 cases of $C$. difficile infection occurred in the United States, approximately one third of which were community-associated infections (i.e., occurred in patients with no recent overnight stay in a health care facility) (15). As much as 35\% of adult and $70 \%$ of pediatric C. difficile infections are community associated $(15,16)$. One study estimated that a $10 \%$ reduction in overall outpatient antibiotic prescribing could reduce community-associated C. difficile infections by $17 \%$ (17). By reducing unnecessary antibiotic prescribing (18-20), antibiotic stewardship can prevent avoidable adverse events resulting from antibiotics.

In 2014 and 2015, respectively, CDC released the Core Elements of Hospital Antibiotic Stewardship Programs (21,22) and the Core Elements of Antibiotic Stewardship for Nursing Homes (23). This 2016 report, Core Elements of Outpatient Antibiotic Stewardship, provides guidance for antibiotic stewardship in outpatient settings and is applicable to any entity interested in improving outpatient antibiotic prescribing and use. The intended audiences for this guidance include clinicians (e.g., physicians, dentists, nurse practitioners, and physician assistants) and clinic leaders in primary care, medical and surgical specialties, emergency departments, retail health and urgent care settings, and dentistry, as well as community pharmacists, other health care professionals, hospital clinics, outpatient facilities, and health care systems involved in outpatient care (Box 1).

Leaders of organizations of any size and within any medical specialty, from single-provider clinics to large health care systems, are encouraged to commit to optimizing antibiotic prescribing and patient safety; implement at least one action in the form of a policy or practice to improve antibiotic prescribing; track and regularly report antibiotic prescribing practices to clinicians or enable clinician self-assessment on antibiotic prescribing; educate clinicians and patients on appropriate antibiotic prescribing; and ensure access to expertise on antibiotic prescribing. Before implementing antibiotic stewardship interventions, clinicians and outpatient clinic and

\section{BOX 1. Entities that are intended audiences for Core Elements of Outpatient Antibiotic Stewardship}

Entities that are intended audiences for this report are outpatient health care professionals and leaders of their respective clinics, departments, facilities, and health care systems.

- Primary care clinics and clinicians: These clinics and clinicians prescribe approximately half of all outpatient antibiotics in the United States.* This includes clinicians specializing in family practice, pediatrics, and internal medicine, all of whom treat a wide variety of patients and conditions that might benefit from antibiotic treatment.

- Outpatient specialty and subspecialty clinics and clinicians: These clinics and clinicians focus on treatment and management of patients with specialized medical conditions that sometimes benefit from antibiotic therapy. These specialties clinics include gastroenterology, dermatology, urology, obstetrics, otolaryngology, and others.

- Emergency departments (EDs) and emergency medicine clinicians: EDs and emergency medicine clinicians are positioned between acute care hospitals and the community and encounter unique challenges, including lack of continuity of care and higher concentration of high-acuity patients, as well as unique opportunities for stewardship interventions, such as greater clinician access to diagnostic resources and the expertise of pharmacists and consultants.

- Retail health clinics and clinicians: These clinics and clinicians provide treatment for routine conditions in retail stores or pharmacies and represent a growing category of health care delivery in the United States.

- Urgent care clinics and clinicians: These clinics and clinicians specialize in treating patients who might need immediate attention or need to be seen after hours but might not need to be seen in EDs.

- Dental clinics and dentists: Dental clinics and dentists use antibiotics as prophylaxis before some dental procedures and for treatment of dental infections.

- Nurse practitioners and physician assistants: These clinicians work in every medical specialty and subspecialty involved in antibiotic prescribing and should be included in antibiotic stewardship efforts.

- Health care systems: Health care systems plan, deliver, and promote health care services and often involve a network of primary and specialty outpatient clinics, urgent care centers, EDs, acute care hospitals, and other facilities that provide health care services. Health care systems can use existing antibiotic stewardship programs or develop new ones to promote appropriate antibiotic prescribing practices in their outpatient facilities as well as across the system.

*Source: CDC. Outpatient antibiotic prescriptions-United States, 2013. Atlanta, GA: US Department of Health and Human Services, CDC; 2013. http:// www.cdc.gov/getsmart/community/pdfs/annual-reportsummary_2013.pdf 
health system leaders can identify opportunities to improve antibiotic prescribing. These opportunities include identifying high-priority conditions for intervention, identifying barriers that lead to deviation from best practices, and establishing standards for antibiotic prescribing based on evidencebased diagnostic criteria and treatment recommendations (Box 2). High-priority conditions are conditions for which clinicians commonly deviate from best practices for antibiotic prescribing and include conditions for which antibiotics are overprescribed, underprescribed, or misprescribed with the wrong antibiotic agent, dose, or duration. Barriers to prescribing antibiotics appropriately might include clinician knowledge gaps about best practices and clinical practice guidelines, clinician perception of patient expectations for antibiotics, perceived pressure to see patients quickly, or clinician concerns about decreased patient satisfaction with clinical visits when antibiotics are not prescribed. Standards for antibiotic prescribing can be based on national clinical practice

BOX 2. Initial steps for antibiotic stewardship: recognize opportunities to improve antibiotic prescribing practices by identifying high-priority conditions, identifying barriers to improving antibiotic prescribing, and establishing standards for antibiotic prescribing

\section{Identify one or more high-priority conditions for intervention.}

High-priority conditions are conditions for which clinicians commonly deviate from best practices for antibiotic prescribing and include conditions for which antibiotics are overprescribed, underprescribed, or misprescribed with the wrong antibiotic agent, dose, or duration.

Examples of types of high-priority conditions for improving antibiotic prescribing include:

- conditions for which antibiotics are overprescribed, such as conditions for which antibiotics are not indicated (e.g., acute bronchitis, nonspecific upper respiratory infection, or viral pharyngitis).*

- conditions for which antibiotics might be appropriate but are overdiagnosed, such as a condition that is diagnosed without fulfilling the diagnostic criteria (e.g., diagnosing streptococcal pharyngitis and prescribing antibiotics without testing for group A Streptococcus). ${ }^{\dagger}$

- conditions for which antibiotics might be indicated but for which the wrong agent, dose, or duration often is selected, such as selecting an antibiotic that is not recommended (e.g., selecting azithromycin rather than amoxicillin or amoxicillin/ clavulanate for acute uncomplicated bacterial sinusitis). $\$$

- conditions for which watchful waiting or delayed prescribing is appropriate but underused (e.g., acute otitis media or acute uncomplicated sinusitis). 9

- conditions for which antibiotics are underused or the need for timely antibiotics is not recognized (e.g., missed diagnoses of sexually transmitted diseases or severe bacterial infections such as sepsis).

\section{Identify barriers that lead to deviation from best practices.}

These might include clinician knowledge gaps about best practices and clinical practice guidelines, clinician perception of patient expectations for antibiotics, perceived pressure to see patients quickly, or clinician concerns about decreased patient satisfaction with clinical visits when antibiotics are not prescribed.

\section{Establish standards for antibiotic prescribing.}

This might include implementation of national clinical practice guidelines and, if applicable, developing facility- or systemspecific clinical practice guidelines to establish clear expectations for appropriate antibiotic prescribing.

* Sources: Shulman ST, Bisno AL, Clegg HW, et al. Clinical practice guideline for the diagnosis and management of group A streptococcal pharyngitis: 2012 update by the Infectious Diseases Society of America. Clin Infect Dis 2012;55:1279-82; Harris AM, Hicks LA, Qaseem A; High Value Care Task Force of the American College of Physicians; CDC. Appropriate antibiotic use for acute respiratory tract infection in adults: advice for high-value care from the American College of Physicians and the Centers for Disease Control and Prevention. Ann Intern Med 2016;164:425-34; and Hersh AL, Jackson MA, Hicks LA; American Academy of Pediatrics Committee on Infectious Diseases. Principles of judicious antibiotic prescribing for upper respiratory tract infections in pediatrics. Pediatrics 2013;132:1146-54.

$\dagger$ Source: Shulman ST, Bisno AL, Clegg HW, et al. Clinical practice guideline for the diagnosis and management of group A streptococcal pharyngitis: 2012 update by the Infectious Diseases Society of America. Clin Infect Dis 2012;55:1279-82.

$\$$ Sources: Chow AW, Benninger MS, Brook I, et al; Infectious Diseases Society of America. IDSA clinical practice guideline for acute bacterial rhinosinusitis in children and adults. Clin Infect Dis 2012;54:e72-112; Wald ER, Applegate KE, Bordley C, et al; American Academy of Pediatrics. Clinical practice guideline for the diagnosis and management of acute bacterial sinusitis in children aged 1 to 18 years. Pediatrics 2013;132:e262-80; and Rosenfeld RM, Piccirillo JF, Chandrasekhar SS, et al. Clinical practice guideline (update): adult sinusitis executive summary. Otolaryngol Head Neck Surg 2015;152:598-609.

ISources: Lieberthal AS, Carroll AE, Chonmaitree T, et al. The diagnosis and management of acute otitis media. Pediatrics 2013;131:e964-99; Wald ER, Applegate KE, Bordley C, et al; American Academy of Pediatrics. Clinical practice guideline for the diagnosis and management of acute bacterial sinusitis in children aged 1 to 18 years. Pediatrics 2013;132:e262-80; and Rosenfeld RM, Piccirillo JF, Chandrasekhar SS, et al. Clinical practice guideline (update): adult sinusitis executive summary. Otolaryngol Head Neck Surg 2015;152:598-609. 
guidelines by national health care professional societies such as the American Academy of Pediatrics, the American College of Physicians, or the Infectious Diseases Society of America or, if applicable, can be based on facility- or system-specific clinical practice guidelines. A summary of current national clinical practice guidelines for common outpatient infections in children and adults is available at http://www.cdc.gov/ getsmart/community/for-hcp/outpatient-hcp/index.html.

Clinicians and clinic leaders can collaborate with relevant partners in the broader health care community to facilitate outpatient antibiotic stewardship (Box 3). To improve antibiotic prescribing, clinic leaders can implement effective strategies to modify prescribing behaviors and align them with evidence-based recommendations for diagnosis and management (1). Clinicians can expect outpatient antibiotic stewardship to improve the quality of patient care, slow the development of community antibiotic resistance, and reduce avoidable adverse drug events caused by unnecessary use of antibiotics $(24,25)$.

\section{Methods}

CDC's Core Elements of Outpatient Antibiotic Stewardship were developed through a combination of consolidating evidence-based antibiotic stewardship practices and building on or adapting known best practices for antibiotic stewardship across other clinical settings, such as the core elements outlined for hospitals $(21,22)$ and nursing homes $(23)$. A narrative review of evidence on outpatient antibiotic stewardship interventions, policies, and practices through May 2016 was conducted. A systematic review was not conducted because at least five systematic reviews on outpatient stewardship interventions have been performed since 2005 (24-28), of which the two most recent were published in 2015 and 2016 $(24,25)$. The narrative review included the five systematic reviews (24-28), articles found through in-text citations, and new articles from a supplemental search of articles published during October 2015-May 2016. Information from selected citations included in the systematic reviews also was considered if it had not been specified previously in the systematic review. The supplemental search of PubMed identified Englishlanguage articles only published during October 2015-May 2016 with the following search terms: "antibiotic stewardship" or "antibiotic prescribing" or "antibiotic prescriptions" or "antimicrobial stewardship" or ("antibiotic" and "stewardship") or ("antimicrobial" and "stewardship"). Articles identified through these methods were prioritized and included on the basis of relevance to outpatient antibiotic stewardship, defined as having 1) clearly stated study objectives to identify factors affecting outpatient antibiotic prescribing or to assess one or more outpatient antibiotic stewardship interventions, 2) been performed in outpatient settings similar to those common in the United States (e.g., study settings in which patients access antibiotics through prescriptions written by a clinician), 3) effectively reported outcomes related to antibiotic stewardship, 4) enrolled subjects with outpatient infections common in the United States, or 5) been previously cited as archetypal studies for stewardship interventions (http://www.cdc.gov/getsmart/community/ improving-prescribing/interventions/index.html); included studies are available online at https://stacks.cdc.gov/view/ cdc/41536). When no peer-reviewed evidence was available, expert opinion was substituted.

CDC identified subject-matter experts in outpatient antibiotic stewardship research, implementation, policy, and practice on the basis of peer-reviewed publications with representation from important outpatient specialties. Subjectmatter experts were identified with expertise in pediatrics, internal medicine, family medicine, emergency medicine, infectious diseases, and pharmacy. CDC provided eight subject-matter experts with a draft of the core elements in April 2016. Subject-matter experts were asked for specific feedback on the feasibility, acceptability, recommended supplementary materials, and potential for the core elements to promote effective and meaningful improvements in outpatient antibiotic prescribing. In addition to written feedback via electronic correspondence, a 1-hour group teleconference was offered to all subject-matter experts, during which verbal feedback from each person was collected. CDC revised and refined the core elements using individual feedback received from the subject-matter experts.

\section{Core Elements of Outpatient Antibiotic Stewardship}

The Core Elements of Outpatient Antibiotic Stewardship follow and are summarized in a clinician checklist (Figure 1) and a facility checklist (Figure 2):

- Commitment: Demonstrate dedication to and accountability for optimizing antibiotic prescribing and patient safety.

- Action for policy and practice: Implement at least one policy or practice to improve antibiotic prescribing, assess whether it is working, and modify as needed.

- Tracking and reporting: Monitor antibiotic prescribing practices and offer regular feedback to clinicians, or have clinicians assess their own antibiotic prescribing practices themselves. 
- Acute care hospitals: Acute care hospitals are a critical component of the continuum of care and often share patients with outpatient clinics. Information sharing between outpatient facilities and acute care hospitals is necessary to monitor local patterns of antibiotic resistance, minimize duplicative testing, facilitate proper patient transition across different care settings, and collaborate on quality improvement initiatives. In addition, hospital-based antibiotic stewardship programs might be a resource for expertise in outpatient antibiotic stewardship initiatives.

- Long-term care facilities: Long-term care facilities provide various services, such as medical and personal care, to patients who are unable to manage independently in the community. Long-term care facilities include rehabilitation facilities, nursing homes, and long-term acute care facilities. Residents of long-term care facilities also are often treated by outpatient clinicians, including medical specialists. Thus, communication between outpatient clinicians and long-term care facilities is critical to antibiotic stewardship efforts.

- State and local health departments: State and local health departments play a crucial role in promoting outpatient antibiotic stewardship by sharing educational resources, connecting local stakeholders and coalitions, designating staff members to improve coordination within and across health care facilities, tracking and reporting local antibiotic resistance threats, and promoting infection prevention and vaccinations.

- Health plans and payers (health insurance companies): Health plans and payers can be a crucial source of data for clinician performance on quality measures for appropriate prescribing, including the Healthcare Effectiveness Data and Information Set (HEDIS) measures. In addition, health plans can provide incentives for antibiotic stewardship through quality-based payments.

- Health care professional societies: Health care professional societies provide an important network of health care professionals and health care leaders to create and share clinical practice guidelines for diagnosis and management of common conditions, provide continuing medical education opportunities for members, and bolster national, local, and regional initiatives promoting appropriate antibiotic use.

- Community pharmacies and pharmacists: Community pharmacies and pharmacists are a trusted source of health care information and provide patient recommendations for nonprescription medications to alleviate symptoms, facilitate medication therapy management, screen patients for drug interactions and allergies, and educate patients regarding appropriate antibiotic use and anticipated side effects. Pharmacies frequently are located near clinics in which patients are seen for management of common infections.

- Local microbiologic laboratories: Local microbiologic laboratories can produce regional or local antibiograms (i.e., tables displaying selected antibiotic sensitivities of bacterial species identified from clinical specimens) relevant to the setting of care, streamline testing and reporting of clinical samples, support rapid diagnostic testing, and provide expertise for interpretation of microbiologic tests.

Other important partners in outpatient stewardship include academic institutions, health professional training programs, information technology and electronic medical record software personnel, consumer advocacy groups, pharmaceutical companies, and health sciences education programs.

- Education and expertise: Provide educational resources to clinicians and patients on antibiotic prescribing, and ensure access to needed expertise on optimizing antibiotic prescribing.

\section{Commitment}

A commitment from all health care team members to prescribe antibiotics appropriately and engage in antibiotic stewardship is critical to improving antibiotic prescribing. Every person involved in patient care, whether directly or indirectly, can act as an antibiotic steward. Each clinician can make the choice to be an effective antibiotic steward during each patient encounter.

Clinicians can demonstrate commitment to appropriate antibiotic prescribing by doing the following:

- Write and display public commitments in support of antibiotic stewardship. For example, inappropriate antibiotic prescriptions for acute respiratory infections were reduced after clinicians displayed, in their examination rooms, a poster showing a letter from the clinician to their patients committing to prescribing antibiotics appropriately (18). This approach also might facilitate patient communication about appropriate antibiotic use. 


\section{FIGURE 1. Clinician checklist for core elements of outpatient antibiotic stewardship}

CDC recommends that outpatient clinicians take steps to implement antibiotic stewardship activities. Use this checklist as a baseline assessment of policies and practices that are in place. Then use the checklist to review progress in expanding stewardship activities on a regular basis (e.g., annually).

\section{Commitment}

1. Can you demonstrate dedication to and accountability for optimizing antibiotic prescribing and patient safety related to antibiotics?

$\square$ Yes $\square$ No

If yes, indicate which of the following are in place.

$\square$ Write and display public commitments in support of antibiotic stewardship.

Action

2. Have you implemented at least one practice to improve antibiotic prescribing?

If yes, indicate which practices which you use. (Select all that apply.)

U Use evidence-based diagnostic criteria and treatment recommendations.

$\square$ Use delayed prescribing practices or watchful waiting, when appropriate.

\section{Tracking and Reporting}

3. Do you monitor at least one aspect of antibiotic prescribing?

If yes, indicate which of the following are being tracked. (Select all that apply.)

$\checkmark$ Self-evaluate antibiotic prescribing practices.

Participate in continuing medical education and quality improvement activities to track and improve antibiotic prescribing.

\section{Education and Expertise}

4. Do you provide education to patients and seek out continuing education on antibiotic prescribing?

If yes, indicate how you provide antibiotic stewardship education. (Select all that apply.)

Use effective communications strategies to educate patients about when antibiotics are and are not needed.

Educate about the potential harms of antibiotic treatment.

Provide patient education materials.

\section{FIGURE 2. Facility checklist for core elements of outpatient antibiotic stewardship}

CDC recommends that outpatient care facilities take steps to implement antibiotic stewardship activities. Use this checklist as a baseline assessment of policies and practices that are in place. Then use the checklist to review progress in expanding stewardship activities on a regular basis (e.g., annually).

Commitment

1. Can your facility demonstrate dedication to and accountability for optimizing antibiotic prescribing and patient safety related to antibiotics?

If yes, indicate which of the following are in place. (Select all that apply.)

$\square$ Identify a single leader to direct antibiotic stewardship activities within a facility.

Include antibiotic stewardship-related duties in position descriptions or job evaluation criteria.

$\square$ Communicate with all clinic staff members to set patient expectations.

Action

2. Has your facility implemented at least one policy or practice to improve antibiotic prescribing?

If yes, indicate which interventions are in place. (Select all that apply.)

P Provide communications skills training for clinicians.

Require explicit written justification in the medical record for nonrecommended antibiotic prescribing.

Provide support for clinical decisions.

Use call centers, nurse hotlines, or pharmacist consultations as triage systems to prevent unnecessary visits.

\section{Tracking and Reporting}

3. Does your facility monitor at least one aspect of antibiotic prescribing?

If yes, indicate which of the following are being tracked. (Select all that apply.)

Track and report antibiotic prescribing for one or more high-priority conditions.
Track and report the percentage of all visits leading to antibiotic prescriptions.

(If already tracking and reporting one of the above) Track and report, at the level of a health care system, complications of antibiotic use and antibiotic resistance trends among common outpatient bacterial pathogens.

Assess and share performance on quality measures and established reduction goals addressing appropriate antibiotic prescribing from health care plans and payers.

Education and Expertise

4. Does your facility provide resources to clinicians and patients on evidence-based antibiotic prescribing?

If yes, indicate how your facility provides antibiotic stewardship education. (Select all that apply.)

Provide face-to-face educational training (academic detailing).

- Provide continuing education activities for clinicians.

$\square$ Ensure timely access to persons with expertise. 
Outpatient clinic and health care system leaders can commit to promoting appropriate antibiotic prescribing by doing any of the following:

- Identify a single leader to direct antibiotic stewardship activities within a facility. Appointing a single leader who is accountable to senior facility leaders is recommended for hospital stewardship programs $(21,22)$, and this approach also might be beneficial in outpatient settings.

- Include antibiotic stewardship-related duties in position descriptions or job evaluation criteria. These duties can be listed for medical directors, nursing leadership positions, and practice management personnel and will help ensure staff members have sufficient time and resources to devote to stewardship. Although evidence in the outpatient settings is lacking, this type of leadership support has been shown to be important for hospital antibiotic stewardship programs (29).

- Communicate with all clinic staff members to set patient expectations. Patient visits for acute illnesses might or might not result in an antibiotic prescription. All staff members in outpatient facilities, including administrative staff members, medical assistants, nurses, allied health professionals, and medical directors, can improve antibiotic prescribing by using consistent messages when communicating with patients about the indications for antibiotics.

\section{Action for Policy and Practice}

Outpatient clinicians and clinic leaders can implement policies and interventions to promote appropriate antibiotic prescribing practices. A stepwise approach with achievable goals can facilitate policy and practice changes and help clinicians and staff members from feeling overwhelmed. As with all quality improvement efforts, assessment and modification of implemented policies and interventions are critical to improving antibiotic prescribing practices. Prioritizing interventions according to feasibility, acceptability, resource commitment, and anticipated barriers to change is important. Action is necessary to transform policy and practice into measurable outcomes.

Clinicians can implement at least one of the following actions to improve antibiotic prescribing:

- Use evidence-based diagnostic criteria and treatment recommendations. When possible, these criteria and recommendations should be based on national or local clinical practice guidelines informed by local pathogen susceptibilities. This can be accomplished by adhering to recommendations from clinical practice guidelines for common infections published by national professional societies such as the American Academy of Pediatrics and the Infectious Diseases Society of America (30-35).

- Use delayed prescribing practices or watchful waiting, when appropriate. Delayed prescribing can be used for patients with conditions that usually resolve without treatment but who can benefit from antibiotics if the conditions do not improve (e.g., acute uncomplicated sinusitis or mild acute otitis media). Clinicians can apply delayed prescribing practices by giving the patient or parent a postdated prescription and providing instructions to fill the prescription after a predetermined period or by instructing the patient to call or return to collect a prescription if symptoms worsen or do not improve (36-40). Watchful waiting means providing symptomatic relief with a clear plan for follow-up if infection symptoms worsen or do not improve. Watchful waiting and delayed antibiotic prescriptions are evidence-based approaches that can safely decrease antibiotic use when used in accordance with clinical practice guidelines (41-44).

Outpatient clinic and health care system leaders can take at least one of the following actions to improve antibiotic prescribing based on established standards or national clinical practice guidelines:

- Provide communications skills training for clinicians. Communications skills training can be used to promote strategies to address patient concerns regarding prognosis, benefits, and harms of antibiotic treatment; management of self-limiting conditions; and clinician concerns regarding managing patient expectations for antibiotics during a clinical visit $(45,46)$.

- Require explicit written justification in the medical record for nonrecommended antibiotic prescribing. This technique has reduced inappropriate prescribing by holding clinicians accountable in the medical record for their decisions (19).

- Provide support for clinical decisions. Clinical decision support, which provides specific information in electronic or print form during the typical workflow, can facilitate accurate diagnoses and effective management of common conditions (e.g., discouraging antibiotic prescribing for acute bronchitis in healthy adults) (47-52).

- Use call centers, nurse hotlines, or pharmacist consultations as triage systems to prevent unnecessary visits. These resources can be used to reduce unnecessary visits for conditions that do not require a clinic visit (53), such as a common cold. 


\section{Tracking and Reporting}

Tracking and reporting clinician antibiotic prescribing, also called audit and feedback, can guide changes in practice and be used to assess progress in improving antibiotic prescribing. When setting up tracking and reporting systems, decisions need to be made about the level at which to track and report (i.e., at the individual clinician level or at the facility level), which outcomes to track and report, and how to obtain the data for tracking and reporting. Sources of data might include automatic electronic medical record extraction, manual periodic chart reviews, or performance data on existing quality measures related to outpatient antibiotic prescribing (e.g., Healthcare Effectiveness Data and Information Set [HEDIS] measures). Analysis can occur at the individual clinician level or at the facility level (i.e., aggregate of all clinician antibiotic prescriptions). The preferred approach, when possible, is to track antibiotic prescribing at the individual clinician level. Individualized feedback provided to clinicians on antibiotic prescribing is an effective way to promote adherence to evidence-based guidelines (20,54-56). Effective feedback interventions have included comparison of clinicians' performance with that of their peers (20), particularly with peers who perform in the top $10 \%$ on quality measures or in adherence to evidence-based guidelines (i.e., top-performing peers) (19). In turn, feedback from clinicians about stewardship interventions can help guide modifications to maximize the impact and improve the acceptability of stewardship interventions (57). In addition, a study that informed certain clinicians that they prescribed more antibiotics than $80 \%$ of their peers also resulted in reductions in overall antibiotic prescribing (58).

Tracking and reporting for identified high-priority conditions can be used to assess whether an antibiotic was appropriate for the assigned diagnosis, whether the diagnostic criteria were met before assigning an antibiotic-appropriate diagnosis, whether the selected antibiotic was the recommended agent, and whether the dose and duration were correct. Outpatient clinicians and clinic or health care system leaders can select outcomes to track and report on the basis of identified opportunities for improvement in their practice or clinics. Systems can track high-priority conditions identified as opportunities to improve clinician adherence to best practices and clinical practice guidelines for antibiotic prescribing (Box 2). For example, acute bronchitis is a common condition for which antibiotics are not recommended in national clinical practice guidelines, yet antibiotics are commonly prescribed $(59,60)$. Therefore, leaders might choose to provide feedback on the percentage of acute bronchitis visits in which a clinician prescribed an antibiotic and include comparisons with their peers' prescribing percentages for acute bronchitis. This paired tracking and reporting approach for selected high-priority conditions has reduced inappropriate antibiotic prescribing and improved antibiotic selection $(19,20)$.

Systems also can track the percentage of visits for which an individual clinician prescribes antibiotics (e.g., number of all antibiotics prescribed for all diagnoses by a clinician divided by the total number of visits for all diagnoses for that clinician). Providing clinicians with these individualized percentages in comparison with their peers has reduced antibiotic prescribing (58) and can help minimize the influence of differences in clinicians' diagnostic coding practices. A practice known as diagnosis shifting occurs when a clinician manipulates a diagnostic code to justify prescribing an antibiotic; for example, a clinician might record the code for pneumonia (which requires an antibiotic) when a patient has acute bronchitis (which does not require an antibiotic). Diagnosis shifting can be missed when tracking and reporting only one high-priority condition (e.g., only acute bronchitis), whereas tracking the percentage of all visits leading to antibiotic prescriptions is not affected by diagnosis shifting. However, when comparing metrics for antibiotic stewardship, the comparability of the clinicians' patient populations should be considered because clinicians might treat patients with different underlying needs for antibiotics (e.g., a clinician who cares for a higher percentage of patients with immunosuppression than other clinicians in their clinic).

Certain health care systems also might be able to track and report the complications of antibiotic use (e.g., C. difficile infections, drug interactions, and adverse drug events) and antibiotic resistance trends among common outpatient bacterial pathogens (24). At the individual or clinic level, smaller sample sizes might make these measures less reliable or useful. In these cases, investigating $C$. difficile infections to assess for possible links to previous ambulatory care visits and antibiotic prescriptions might be used as a marker for possible adverse drug events.

Both clinicians and clinic leaders can be involved in antibiotic stewardship. Clinicians can track and report their own antibiotic prescribing practices by doing at least one of the following:

- Self-evaluate antibiotic prescribing practices. Clinicians can use self-evaluations to align their antibiotic prescribing practices with updated evidence-based recommendations and clinical practice guidelines.

- Participate in continuing medical education and quality improvement activities to track and improve antibiotic prescribing. Activities can be tailored by clinical specialty if conducted through health professional organizations and also might be used to meet licensure and other education and quality improvement requirements. 
Outpatient clinic or health care system leaders can do at least one of the following:

- Implement at least one antibiotic prescribing tracking and reporting system. Outcomes to be tracked can include high-priority conditions that have been identified as opportunities for improvement in that clinic, the percentage of all visits leading to antibiotic prescriptions, and, for health systems, complications of antibiotic use and antibiotic resistance trends (if antibiotic prescribing outcomes are already being tracked). Outcomes can be tracked and reported by individual clinicians (which is preferred) and by facilities.

- Assess and share performance on quality measures and established reduction goals addressing appropriate antibiotic prescribing from health care plans and payers. The National Strategy for Combating Antibiotic-Resistant Bacteria aims to reduce inappropriate antibiotic use by $50 \%$ for monitored conditions in outpatient settings by 2020 (61). Current HEDIS measures include quality measures for appropriate testing for children with pharyngitis, appropriate treatment for children with upper respiratory infections (i.e., avoidance of antibiotics), and avoidance of antibiotic treatment in adults with acute bronchitis (62).

\section{Education and Expertise}

Education on appropriate antibiotic use can involve patients and clinicians. Education for patients and family members can improve health literacy and augment efforts to improve antibiotic use. Education for clinicians and clinic staff members can reinforce appropriate antibiotic prescribing and improve the quality of care $(56,63,64)$. Deficits in clinician knowledge are seldom the only barrier to prescribing antibiotics appropriately in the outpatient setting. Effective clinician education often includes reviewing guidelines for appropriate antibiotic prescribing while also addressing the psychosocial pressures that influence antibiotic prescribing practices of clinicians (e.g., clinicians' concerns about patient satisfaction). Access to colleagues and consultants with expertise (e.g., pharmacists and specialists) also is a valuable resource for improving antibiotic prescribing.

Clinicians can educate patients and families about appropriate antibiotic use by doing at least one of the following:

- Use effective communications strategies to educate patients about when antibiotics are and are not needed. For example, patients should be informed that antibiotic treatment for viral infections provides no benefit and thus should not be used for viral infections. Patients also should be informed that certain bacterial infections (e.g., mild ear and sinus infections) might improve without antibiotics. Explanations of when antibiotics are not needed can be combined with recommendations for symptom management; this combination of messages has been associated with visit satisfaction (65). In addition, providing recommendations for when to seek medical care if patients worsen or do not improve (i.e., a contingency plan) has been associated with higher visit satisfaction scores among patients who expected but were not prescribed antibiotics (66).

- Educate patients about the potential harms of antibiotic treatment. Potential harms might include common and sometimes serious side effects of antibiotics, including nausea, abdominal pain, diarrhea, $C$. difficile infection, allergic reactions, and other serious reactions. Parents of young children, in particular, want to be informed about possible adverse events associated with antibiotics (67). In addition, increasing evidence suggests antibiotic use in infancy and childhood is linked with allergic, infectious, and autoimmune diseases, likely through disturbing the microbiota (i.e., microorganisms within and on the human body) (68).

- Provide patient education materials. These materials might include information on appropriate antibiotic use, potential adverse drug events from antibiotics, and available resources regarding symptomatic relief for common infections. Educational materials on management of common infections are available online from CDC (http://www.cdc.gov/getsmart).

Outpatient clinic and health care system leaders can provide education to clinicians and ensure access to expertise by doing at least one of the following:

- Provide face-to-face educational training (academic detailing). This training can be provided by peers, colleagues, or opinion leaders, including other clinicians and pharmacists, and uses reinforcement techniques and peer-to-peer comparisons to facilitate changes in antibiotic prescribing practices (69-71).

- Provide continuing education activities for clinicians. Relevant continuing education activities include those that address appropriate antibiotic prescribing, adverse drug events, and communication strategies about appropriate antibiotic prescribing that can improve patient satisfaction. In particular, communications training in which clinicians were taught to assess patient expectations, discuss the risks and benefits of antibiotic treatment, provide recommendations for when to seek medical care if worsening or not improving (a contingency plan), and assess the patient's understanding of the communicated information led to sustained decreases in inappropriate antibiotic prescribing $(46,72)$. 
- Ensure timely access to persons with expertise. Persons with expertise might include pharmacists or medical and surgical consultants who can assist clinicians in improving antibiotic prescribing for patients with conditions requiring specialty care. For example, in hospitals, pharmacists with infectious disease training have been effective and important members of antibiotic stewardship programs, and in hospital stewardship programs these types of pharmacists have been associated with improved patient outcomes and overall cost savings for the hospital (73). The expertise needed might differ among outpatient facilities and can be determined by each facility.

\section{Future Directions}

The Core Elements of Outpatient Antibiotic Stewardship provides a framework for improving antibiotic prescribing. Expanding horizons for outpatient health care delivery, such as outpatient parenteral antibiotic therapy, telemedicine and telehealth, and urgent care and retail clinics, might require unique stewardship approaches. Several studies have been published that show the benefit of antibiotic stewardship interventions in traditional primary care clinics $(18,38,42)$. Additional implementation research is needed to determine which outpatient stewardship interventions work best in different outpatient settings, effective strategies to implement interventions, and sustainable approaches to outpatient stewardship.

Acute respiratory tract infections have been a focus of outpatient stewardship because these are the most common conditions leading to antibiotic treatment. However, additional efforts are needed to optimize stewardship efforts for other situations and syndromes that commonly lead to antibiotic use in the outpatient setting, including ambulatory procedures, dental prophylaxis, genitourinary infections, acne and other skin and soft tissue conditions, and chronic obstructive pulmonary disease.

\section{Conclusion}

Although the core elements provide a framework for outpatient antibiotic stewardship, implementing the elements requires a thoughtful and consistent effort to achieve desired outcomes. This includes developing strategies and preparing individuals, facilities, or organizations for change; developing and testing stewardship interventions; identifying and addressing barriers to change; and evaluating progress toward stated goals. Outpatient settings remain a crucial component of antibiotic stewardship in the United States. Establishing effective antibiotic stewardship interventions can protect patients and optimize clinical outcomes in outpatient health care settings.

\section{Acknowledgments}

Jonathan A. Finkelstein, MD, Boston Children's Hospital, Harvard Medical School, Boston, Massachusetts; Jeffrey S. Gerber, MD, $\mathrm{PhD}$, Children's Hospital of Philadelphia, University of Pennsylvania Perelman School of Medicine, Philadelphia, Pennsylvania; Adam L. Hersh, MD, PhD, University of Utah, Salt Lake City, Salt Lake City, Utah; David Y. Hyun, MD, The Pew Charitable Trusts, Washington, DC; Jeffrey A. Linder, MD, Brigham and Women's Hospital, Harvard Medical School, Boston, Massachusetts; Larissa S. May, MD, University of California—Davis, Sacramento, California; Daniel Merenstein, MD, Georgetown University Medical Center, Washington, DC; Katie J. Suda, PharmD, Department of Veterans Affairs, University of Illinois at Chicago, Chicago, Illinois; Kelly O'Neill, Austyn Dukes, and Rachel Robb, National Center for Emerging and Zoonotic Infectious Diseases, CDC, Atlanta, Georgia; Rachel Zetts, The Pew Charitable Trusts, Washington, DC.

\section{References}

1. CDC. Antibiotic resistance threats in the United States, 2013 [Internet]. Atlanta, GA: US Department of Health and Human Services, CDC; 2013. http:/www.cdc.gov/drugresistance/threat-report-2013/index.html

2. CDC. Office-related antibiotic prescribing for persons aged $\leq 14$ yearsUnited States, 1993-1994 to 2007-2008. MMWR Morb Mortal Wkly Rep 2011;60:1153-6.

3. Shapiro DJ, Hicks LA, Pavia AT, Hersh AL. Antibiotic prescribing for adults in ambulatory care in the USA, 2007-09. J Antimicrob Chemother 2014;69:234-40. http://dx.doi.org/10.1093/jac/dkt301

4. Gonzales R, Malone DC, Maselli JH, Sande MA. Excessive antibiotic use for acute respiratory infections in the United States. Clin Infect Dis 2001;33:757-62. http://dx.doi.org/10.1086/322627

5. Fleming-Dutra KE, Hersh AL, Shapiro DJ, et al. Prevalence of inappropriate antibiotic prescriptions among U.S. ambulatory care visits, 2010-2011. JAMA 2016;315:1864-73. http://dx.doi.org/10.1001/ jama.2016.4151

6. Barlam TF, Cosgrove SE, Abbo LM, et al. Implementing an Antibiotic Stewardship Program: Guidelines by the Infectious Diseases Society of America and the Society for Healthcare Epidemiology of America. Clin Infect Dis 2016;62:e51-77 http://dx.doi.org/10.1093/cid/ciw217

7. Seppälä H, Klaukka T, Vuopio-Varkila J, et al; Finnish Study Group for Antimicrobial Resistance. The effect of changes in the consumption of macrolide antibiotics on erythromycin resistance in group A streptococci in Finland. N Engl J Med 1997;337:441-6. http://dx.doi.org/10.1056/ NEJM199708143370701

8. Suda KJ, Hicks LA, Roberts RM, Hunkler RJ, Danziger LH. A national evaluation of antibiotic expenditures by healthcare setting in the United States, 2009. J Antimicrob Chemother 2013;68:715-8. http://dx.doi. org/10.1093/jac/dks445

9. Public Health England. English Surveillance Programme for Antimicrobial Utilisation and Resistance (ESPAUR): report 2014 [Internet]. London, England: Public Health England; 2014. https:// www.gov.uk/government/uploads/system/uploads/attachment_data/ file/362374/ESPAUR_Report_2014_3_.pdf

10. Public Health Agency of Sweden, National Veterinary Institute. Consumption of antibiotics and occurrence of antibiotic resistance in Sweden [Internet]. Swedres-Svarm 2014. Solna and Uppsala, Sweden: Public Health Agency of Sweden, National Veterinary Institute; 2015. Report No. ISSN 1650-6332. https://www.folkhalsomyndigheten.se/ pagefiles/20281/Swedres-Svarm-2014-14027.pdf

11. CDC. Outpatient antibiotic prescriptions - United States, 2013. Atlanta, GA: US Department of Health and Human Services, CDC; 2013. http:// www.cdc.gov/getsmart/community/pdfs/annual-reportsummary_2013.pdf 
12. Hersh AL, Shapiro DJ, Pavia AT, Shah SS. Antibiotic prescribing in ambulatory pediatrics in the United States. Pediatrics 2011;128:105361. http://dx.doi.org/10.1542/peds.2011-1337

13. Shehab N, Patel PR, Srinivasan A, Budnitz DS. Emergency department visits for antibiotic-associated adverse events. Clin Infect Dis 2008;47:735-43. http://dx.doi.org/10.1086/591126

14. Kutty PK, Woods CW, Sena AC, et al. Risk factors for and estimated incidence of community-associated Clostridium difficile infection, North Carolina, USA. Emerg Infect Dis 2010;16:197-204. http://dx.doi. org/10.3201/eid1602.090953

15. Lessa FC, Mu Y, Bamberg WM, et al. Burden of Clostridium difficile infection in the United States. N Engl J Med 2015;372:825-34. http:// dx.doi.org/10.1056/NEJMoa1408913

16. Wendt JM, Cohen JA, Mu Y, et al. Clostridium difficile infection among children across diverse U.S. geographic locations. Pediatrics 2014;133:651-8. http://dx.doi.org/10.1542/peds.2013-3049

17. Dantes R, Mu Y, Hicks LA, et al. Association between outpatient antibiotic prescribing practices and community-associated Clostridium difficile infection. Open Forum Infect Dis 2015;2:ofv113. http://dx.doi. org/10.1093/ofid/ofv113

18. Meeker D, Knight TK, Friedberg MW, et al. Nudging guidelineconcordant antibiotic prescribing: a randomized clinical trial. JAMA Intern Med 2014;174:425-31. http://dx.doi.org/10.1001/ jamainternmed.2013.14191

19. Meeker D, Linder JA, Fox CR, et al. Effect of behavioral interventions on inappropriate antibiotic prescribing among primary care practices: a randomized clinical trial. JAMA 2016;315:562-70. http://dx.doi. org/10.1001/jama.2016.0275

20. Gerber JS, Prasad PA, Fiks AG, et al. Effect of an outpatient antimicrobial stewardship intervention on broad-spectrum antibiotic prescribing by primary care pediatricians: a randomized trial. JAMA 2013;309:234552. http://dx.doi.org/10.1001/jama.2013.6287

21. CDC. Core elements of hospital antibiotic stewardship programs [Internet]. Atlanta, GA: US Department of Health and Human Services, CDC; 2014. http:/www.cdc.gov/getsmart/healthcare/implementation/ core-elements.html

22. Pollack LA, Srinivasan A. Core elements of hospital antibiotic stewardship programs from the Centers for Disease Control and Prevention. Clin Infect Dis 2014;59(Suppl 3):S97-100. http://dx.doi. org/10.1093/cid/ciu542

23. CDC. Core elements of antibiotic stewardship for nursing homes [Internet]. Atlanta, GA: US Department of Health and Human Services, CDC; 2014. http://www.cdc.gov/longtermcare/prevention/antibioticstewardship.html

24. Drekonja DM, Filice GA, Greer N, et al. Antimicrobial stewardship in outpatient settings: a systematic review. Infect Control Hosp Epidemiol 2015;36:142-52. http://dx.doi.org/10.1017/ice.2014.41

25. McDonagh M, Peterson K, Winthrop K, Cantor A, Holzhammer B, Buckley DI. Improving antibiotic prescribing for uncomplicated acute respiratory tract infections. AHRQ Comparative Effectiveness Reviews 2016.

26. Ranji SR, Steinman MA, Shojania KG, Gonzales R. Interventions to reduce unnecessary antibiotic prescribing: a systematic review and quantitative analysis. Med Care 2008;46:847-62. http://dx.doi. org/10.1097/MLR.0b013e318178eabd

27. Arnold SR, Straus SE. Interventions to improve antibiotic prescribing practices in ambulatory care. Cochrane Database Syst Rev 2005; 4:CD003539.

28. van der Velden AW, Pijpers EJ, Kuyvenhoven MM, Tonkin-Crine SK, Little P, Verheij TJ. Effectiveness of physician-targeted interventions to improve antibiotic use for respiratory tract infections. Br J Gen Pract 2012;62:801-7. http://dx.doi.org/10.3399/bjgp12X659268
29. Pollack LA, van Santen KL, Weiner LM, Dudeck MA, Edwards JR, Srinivasan A. Antibiotic stewardship programs in U.S. acute care hospitals: findings from the 2014 National Healthcare Safety Network Annual Hospital Survey. Clin Infect Dis 2016;63:443-9 http://dx.doi. org/10.1093/cid/ciw323

30. Chow AW, Benninger MS, Brook I, et al; Infectious Diseases Society of America. IDSA clinical practice guideline for acute bacterial rhinosinusitis in children and adults. Clin Infect Dis 2012;54:e72-112. http://dx.doi. org/10.1093/cid/cis370

31. Gupta K, Hooton TM, Naber KG, et al; Infectious Diseases Society of America; European Society for Microbiology and Infectious Diseases. International clinical practice guidelines for the treatment of acute uncomplicated cystitis and pyelonephritis in women: a 2010 update by the Infectious Diseases Society of America and the European Society for Microbiology and Infectious Diseases. Clin Infect Dis 2011;52:e103-20. http://dx.doi.org/10.1093/cid/ciq257

32. Lieberthal AS, Carroll AE, Chonmaitree T, et al. The diagnosis and management of acute otitis media. Pediatrics 2013;131:e964-99. http:// dx.doi.org/10.1542/peds.2012-3488

33. Mandell LA, Wunderink RG, Anzueto A, et al; Infectious Diseases Society of America; American Thoracic Society. Infectious Diseases Society of America/American Thoracic Society consensus guidelines on the management of community-acquired pneumonia in adults. Clin Infect Dis 2007;44(Suppl 2):S27-72. http://dx.doi.org/10.1086/511159

34. Shulman ST, Bisno AL, Clegg HW, et al. Clinical practice guideline for the diagnosis and management of group A streptococcal pharyngitis: 2012 update by the Infectious Diseases Society of America. Clin Infect Dis 2012;55:1279-82. http://dx.doi.org/10.1093/cid/cis847

35. Wald ER, Applegate KE, Bordley C, et al; American Academy of Pediatrics. Clinical practice guideline for the diagnosis and management of acute bacterial sinusitis in children aged 1 to 18 years. Pediatrics 2013;132:e262-80. http://dx.doi.org/10.1542/peds.2013-1071

36. Little P, Moore M, Kelly J, et al; PIPS Investigators. Delayed antibiotic prescribing strategies for respiratory tract infections in primary care: pragmatic, factorial, randomised controlled trial. BMJ 2014;348:g1606. http://dx.doi.org/10.1136/bmj.g1606

37. Little P, Rumsby K, Kelly J, et al. Information leaflet and antibiotic prescribing strategies for acute lower respiratory tract infection: a randomized controlled trial. JAMA 2005;293:3029-35. http://dx.doi. org/10.1001/jama.293.24.3029

38. de la Poza Abad M, Mas Dalmau G, Moreno Bakedano M, et al; Delayed Antibiotic Prescription (DAP) Group. Prescription strategies in acute uncomplicated respiratory infections: a randomized clinical trial. JAMA Intern Med 2016;176:21-9. http://dx.doi.org/10.1001/ jamainternmed.2015.7088

39. Chao JH, Kunkov S, Reyes LB, Lichten S, Crain EF. Comparison of two approaches to observation therapy for acute otitis media in the emergency department. Pediatrics 2008;121:e1352-6. http://dx.doi. org/10.1542/peds.2007-2278

40. Francis NA, Gillespie D, Nuttall J, et al. Delayed antibiotic prescribing and associated antibiotic consumption in adults with acute cough. Br J Gen Pract 2012;62:e639-46. http://dx.doi.org/10.3399/bjgp12X654614

41. McCormick DP, Chonmaitree T, Pittman C, et al. Nonsevere acute otitis media: a clinical trial comparing outcomes of watchful waiting versus immediate antibiotic treatment. Pediatrics 2005;115:1455-65. http:// dx.doi.org/10.1542/peds.2004-1665

42. Siegel RM, Kiely M, Bien JP, et al. Treatment of otitis media with observation and a safety-net antibiotic prescription. Pediatrics 2003;112:527-31. http://dx.doi.org/10.1542/peds.112.3.527

43. Spiro DM, Tay KY, Arnold DH, Dziura JD, Baker MD, Shapiro ED. Wait-and-see prescription for the treatment of acute otitis media: a randomized controlled trial. JAMA 2006;296:1235-41. http://dx.doi. org/10.1001/jama.296.10.1235 
44. Rosenfeld RM, Piccirillo JF, Chandrasekhar SS, et al. Clinical practice guideline (update): Adult Sinusitis Executive Summary. Otolaryngol Head Neck Surg 2015;152:598-609. http://dx.doi. org/10.1177/0194599815574247

45. Little P, Stuart B, Francis N, et al; GRACE consortium. Effects of internet-based training on antibiotic prescribing rates for acute respiratory-tract infections: a multinational, cluster, randomised, factorial, controlled trial. Lancet 2013;382:1175-82. http://dx.doi. org/10.1016/S0140-6736(13)60994-0

46. Cals JW, de Bock L, Beckers PJ, et al. Enhanced communication skills and C-reactive protein point-of-care testing for respiratory tract infection: 3.5-year follow-up of a cluster randomized trial. Ann Fam Med 2013;11:157-64. http://dx.doi.org/10.1370/afm.1477

47. McGinn TG, McCullagh L, Kannry J, et al. Efficacy of an evidence-based clinical decision support in primary care practices: a randomized clinical trial. JAMA Intern Med 2013;173:1584-91. http://dx.doi.org/10.1001/ jamainternmed.2013.8980

48. Jenkins TC, Irwin A, Coombs L, et al. Effects of clinical pathways for common outpatient infections on antibiotic prescribing. Am J Med 2013;126:327-335.e12. http://dx.doi.org/10.1016/j. amjmed.2012.10.027

49. Gonzales R, Anderer T, McCulloch CE, et al. A cluster randomized trial of decision support strategies for reducing antibiotic use in acute bronchitis. JAMA Intern Med 2013;173:267-73. http://dx.doi. org/10.1001/jamainternmed.2013.1589

50. Rattinger GB, Mullins CD, Zuckerman IH, et al. A sustainable strategy to prevent misuse of antibiotics for acute respiratory infections. PLoS One 2012;7:e51147. http://dx.doi.org/10.1371/journal.pone.0051147

51. Linder JA, Schnipper JL, Tsurikova R, et al. Documentation-based clinical decision support to improve antibiotic prescribing for acute respiratory infections in primary care: a cluster randomised controlled trial. Inform Prim Care 2009;17:231-40.

52. Forrest CB, Fiks AG, Bailey LC, et al. Improving adherence to otitis media guidelines with clinical decision support and physician feedback. Pediatrics 2013;131:e1071-81. http://dx.doi.org/10.1542/ peds.2012-1988

53. Harper R, Temkin T, Bhargava R. Optimizing the use of telephone nursing advice for upper respiratory infection symptoms. Am J Manag Care 2015;21:264-70.

54. Metlay JP, Camargo CA Jr, MacKenzie T, et al; IMPAACT Investigators. Cluster-randomized trial to improve antibiotic use for adults with acute respiratory infections treated in emergency departments. Ann Emerg Med 2007;50:221-30. http://dx.doi.org/10.1016/j. annemergmed.2007.03.022

55. Finkelstein JA, Huang SS, Kleinman K, et al. Impact of a 16-community trial to promote judicious antibiotic use in Massachusetts. Pediatrics 2008;121:e15-23. http://dx.doi.org/10.1542/peds.2007-0819

56. Butler CC, Simpson SA, Dunstan F, et al. Effectiveness of multifaceted educational programme to reduce antibiotic dispensing in primary care: practice based randomised controlled trial. BMJ 2012;344:d8173. http:// dx.doi.org/10.1136/bmj.d8173

57. Dempsey PP, Businger AC, Whaley LE, Gagne JJ, Linder JA. Primary care clinicians' perceptions about antibiotic prescribing for acute bronchitis: a qualitative study. BMC Fam Pract 2014;15:194. http:// dx.doi.org/10.1186/s12875-014-0194-5

58. Hallsworth M, Chadborn T, Sallis A, et al. Provision of social norm feedback to high prescribers of antibiotics in general practice: a pragmatic national randomised controlled trial. Lancet 2016;387:1743-52. http:// dx.doi.org/10.1016/S0140-6736(16)00215-4
59. Harris AM, Hicks LA, Qaseem A; High Value Care Task Force of the American College of Physicians and for the Centers for Disease Control and Prevention. Appropriate antibiotic use for acute respiratory tract infection in adults: advice for high-value care from the American College of Physicians and the Centers for Disease Control and Prevention. Ann Intern Med 2016;164:425-34. http://dx.doi.org/10.7326/M15-1840

60. Hersh AL, Jackson MA, Hicks LA; American Academy of Pediatrics Committee on Infectious Diseases. Principles of judicious antibiotic prescribing for upper respiratory tract infections in pediatrics. Pediatrics 2013;132:1146-54. http://dx.doi.org/10.1542/peds.2013-3260

61. The White House. National action plan for combating antibioticresistant bacteria [Internet]. Washington, DC: The White House; 2015. https://www.whitehouse.gov/sites/default/files/docs/national_action_ plan_for_combating_antibotic-resistant_bacteria.pdf

62. National Committee for Quality Assurance. HEDIS \& performance measurement [Internet]. Washington, DC: National Committee for Quality Assurance; 2016. http://www.ncqa.org/ hedis-quality-measurement

63. Harris RH, MacKenzie TD, Leeman-Castillo B, et al. Optimizing antibiotic prescribing for acute respiratory tract infections in an urban urgent care clinic. J Gen Intern Med 2003;18:326-34. http://dx.doi. org/10.1046/j.1525-1497.2003.20410.x

64. Juzych NS, Banerjee M, Essenmacher L, Lerner SA. Improvements in antimicrobial prescribing for treatment of upper respiratory tract infections through provider education. J Gen Intern Med 2005;20:9015. http://dx.doi.org/10.1111/j.1525-1497.2005.0198.x

65. Mangione-Smith R, Zhou C, Robinson JD, Taylor JA, Elliott MN, Heritage J. Communication practices and antibiotic use for acute respiratory tract infections in children. Ann Fam Med 2015;13:221-7. http://dx.doi.org/10.1370/afm.1785

66. Mangione-Smith R, McGlynn EA, Elliott MN, McDonald L, Franz CE, Kravitz RL. Parent expectations for antibiotics, physicianparent communication, and satisfaction. Arch Pediatr Adolesc Med 2001;155:800-6. http://dx.doi.org/10.1001/archpedi.155.7.800

67. Roberts RM, Albert AP, Johnson DD, Hicks LA. Can improving knowledge of antibiotic-associated adverse drug events reduce parent and patient demand for antibiotics? Health Serv Res Manag Epidemiol 2015;2. http://dx.doi.org/10.1177/2333392814568345

68. Vangay P, Ward T, Gerber JS, Knights D. Antibiotics, pediatric dysbiosis, and disease. Cell Host Microbe 2015;17:553-64. http://dx.doi. org/10.1016/j.chom.2015.04.006

69. Gjelstad S, Høye S, Straand J, Brekke M, Dalen I, Lindbæk M. Improving antibiotic prescribing in acute respiratory tract infections: cluster randomised trial from Norwegian general practice (prescription peer academic detailing (Rx-PAD) study). BMJ 2013;347:f4403. http:// dx.doi.org/10.1136/bmj.f4403

70. Solomon DH, Van Houten L, Glynn RJ, et al. Academic detailing to improve use of broad-spectrum antibiotics at an academic medical center. Arch Intern Med 2001;161:1897-902. http://dx.doi.org/10.1001/ archinte.161.15.1897

71. Soumerai SB, Avorn J. Principles of educational outreach ('academic detailing') to improve clinical decision making. JAMA 1990;263:54956. http://dx.doi.org/10.1001/jama.1990.03440040088034

72. Cals JWL, Scheppers NAM, Hopstaken RM, et al. Evidence based management of acute bronchitis; sustained competence of enhanced communication skills acquisition in general practice. Patient Educ Couns 2007;68:270-8. http://dx.doi.org/10.1016/j.pec.2007.06.014

73. Yu K, Rho J, Morcos M, et al. Evaluation of dedicated infectious diseases pharmacists on antimicrobial stewardship teams. Am J Health Syst Pharm 2014;71:1019-28. http://dx.doi.org/10.2146/ajhp130612 

The Morbidity and Mortality Weekly Report (MMWR) Series is prepared by the Centers for Disease Control and Prevention (CDC) and is available free of charge in electronic format. To receive an electronic copy each week, visit MMWR's free subscription page at http://www.cdc.gov/mmwr/mmwrsubscribe.html. Paper copy subscriptions are available through the Superintendent of Documents, U.S. Government Printing Office, Washington, DC 20402; telephone 202-512-1800.

Readers who have difficulty accessing this PDF file may access the HTML file at http://www.cdc.gov/mmwr/volumes/65/rr/rr6506a1.htm?s_cid=rr6506a1_w. Address all inquiries about the $M M W R$ Series, including material to be considered for publication, to Executive Editor, MMWR Series, Mailstop E-90, CDC, 1600 Clifton Rd., N.E., Atlanta, GA 30329-4027 or to mmwrq@cdc.gov.

All material in the MMWR Series is in the public domain and may be used and reprinted without permission; citation as to source, however, is appreciated. Use of trade names and commercial sources is for identification only and does not imply endorsement by the U.S. Department of Health and Human Services.

References to non-CDC sites on the Internet are provided as a service to $M M W R$ readers and do not constitute or imply endorsement of these organizations or their programs by CDC or the U.S. Department of Health and Human Services. CDC is not responsible for the content of these sites. URL addresses listed in $M M W R$ were current as of the date of publication.

ISSN: $1057-5987$ (Print) 